\title{
LA ODISEA DE LA ESPECIE: EL PORVENIR LEJANO DE LA HUMANIDAD
}

\author{
María Lucrecia Rovaletti*
}

Resumen: A partir de la definición del hombre como "ser práxico", se plantea la noción de "trascendencia técnica" u "operatoria". Dado que la tecnociencia considera que los límites se establecen para ser transgredidos, se la compara con el concepto de "utopía" como "operador de trascendencia"(S. Breton). Esto nos lleva a pensar en una nueva "evolución", ya no fruto de los cambios naturales sino del poder tecnocientífico humano. Entonces, ante esto caben dos alternativas: la de los enfrentamientos y desgarros, o la del debate sereno y argumentado de cada situación.

Palabras clave: tecnociencia, utopía, ética, bioética

\section{THE SPECIES' ODYSSEY: HUMANITY'S DISTANT FUTURE}

\begin{abstract}
The notion of "technical transcendency" or "operatory" is raised starting from man's definition as a "praxis being". Since technoscience establishes that limits are settled to be transgressed, it is compared with the concept of "utopia" as an "transcendental operator" (S. Breton). This leads us to think about a new "evolution" not due to natural changes, but to human technoscientific power. Thus, we have two alternatives: confrontations and breaches, or a fair and reasoned debate of each situation.
\end{abstract}

Key words: technoscience, utopia, ethics, bioethics

\section{A ODISSÉIA DA ESPÉCIE: O DISTANTE FUTURO DA HUMANIDADE}

Resumo: A partir da definição de homem como "ser práxico", se coloca a noção de "transcendência técnica" ou "operacional". Dado que a tecnolciência considera que os limites se estabelecem para ser transgredidos, compara-se com o conceito de "utopia" como "operador de transcendencia" ( S. Breton). Isto nos leva a pensar numa nova "evolução", que não seja fruto das mudanças naturais, mas do poder tecnocientífico humano. Então, frente a ele surgem duas alternativas: a dos enfrentamentos e desvios, ou a do debate sereno e argumentado de cada situação.

Palavras chaves: tecnociencia, utopia, ética, bioética

* Universidad de Buenos Aires. CONICET. Fundación Mainetti 
“Por qué se le ocurrió a la naturaleza organizar un ser expuesto a la descomunal capacidad del error y perturbabilidad de la conciencia"?(1, p.14)

\section{La técnica como remedio de la insuficiencia biológica}

Para comprender al hombre, Gehlen parte de las condiciones de la existencia de este "ser, especial e incomparable al que le faltan todas las condiciones vitales del animal", que tiene que encontrar ante sí y en sí mismo una serie de "tareas" para poder mantener, prorrogar y llevar adelante su vida.

$\mathrm{Si}$ "la naturaleza le ha concedido una posición especial al hombre o, dicho de otra manera, en el hombre ha intentado una dirección de la evolución no existente antes, no probada todavía", si ella lo entregó "a todos los peligros de posibles alteraciones o extravíos que se encierran en ese no 'estar firmemente establecido', en esa obligación de afirmarse a sí mismo" y en ese tener que disponer de sí mismo, es porque "tuvo que existir un motivo muy serio(1)".

Es por ello que el hombre tiene que tomar posición frente a las cosas, y a esos actos los denomina "acciones". "El hombre es el ser práxico" que comercia, que trata-con ${ }^{1}$ cosas $(1, p .35)$; pero es también el que toma posición respecto de sí mismo y "se hace algo" no como un lujo sino por sus propios condicionamientos: es un "ser de doma", de amaestramiento o adiestramiento, de educación. Por eso cuando el hombre está dejado de sí mismo y desperdicia su tarea vitalmente necesaria, es un "ser amenazado o en riesgo", con una posibilidad constitucional de malograrse. De allí la ne-

1 Más aún, la determinación del hombre a la acción es una ley estructural que trasciende a todas las funciones y operaciones humanas, y surge precisamente de su organización físicabiológica. cesidad de que el hombre sea "pre-visor", orientado "a lo lejano, a lo no presente en el espacio y el tiempo". Precisamente por eso está erecto, circunspecto, es decir, mirando a su alrededor con sus manos libres.

A diferencia del animal, el hombre aprende de la experiencia, sin que ella tenga que ver siempre con una situación biológicamente extraordinaria. Hay en él una descarga, liberación o exención de su comportamiento respecto de las pulsiones, que convierte al aprendizaje en una verdadera novedad. Si bien está determinado por la carencia - es decir, la no adaptación, la no especialización-, puede resarcirse de ello por la "capacidad de trabajo" o por el "don de la acción".

Gehlen -como Alsberg, Ortega, Tinland y otros-deriva la necesidad de la técnica de la deficiencia orgánica del ser humano. Plantea un principio de sustitución de órganos, junto al cual aparecen luego los de descarga y de superación de órganos. Así, la piedra lanzada con la mano alivia al puño que golpea $\mathrm{y}$, al mismo tiempo, lo aventaja respecto a sus efectos; el coche y la cabalgadura nos eximen del andar y superan con creces su alcance; la bestia de carga hace visible el principio de descarga; el avión sustituye las alas y sobrepasa holgadamente todo esfuerzo orgánico de vuelo. Esto mostraría la relación esencial entre el hombre y la técnica $^{2}$, es decir, entre la inteligencia inventiva del hombre, su equipamiento orgánico y la capacidad de aumento de sus necesidades.

El hombre, al estar abierto al "mundo", carece de la adaptación animal a un ambientefragmento; "frente a él no hay un medio ambiente (circun-mundo) con distribución de sig-

2 Gehlen no pretende apreciar la totalidad del patrimonio anímico humano con esta sola función, pues no deja de lado el lenguaje ni las instituciones, aunque éstas se encuentren en estrecha interacción histórica con las formas técnicas de conducción de la vida, de la legislación del trabajo y la economía 
nificados realizada por vía instintiva". Al contrario, esta apertura significa más bien una carga, pues lo somete constantemente "a una sobreabundancia de estímulos de tipo no animal, a una plétora de impresiones 'sin finalidad' que afluyen a él y que él tiene que dominar de alguna manera(1, pp. 39-41)". El mundo se le presenta, expresado negativamente, como un campo de sorpresas, de estructura imprevisible, que sólo puede ser elaborado, es decir experimentado, mediante "pre-visión" y "pro-videncia". Sin embargo, al tener que apropiarse por la acción de esa riqueza que el mundo le ofrece, éste se convierte en un "campo ilimitado de admiración(1, p. 151).

"Sin ambiente específico al cual esté adaptado; sin modelos innatos adecuados de movimiento y conducta [...]; sin órganos e instintos, pobre sensorialmente, desarmado, desnudo, de exterior embrionario; instintivamente inseguro -por la misma información proveniente de sus impulsos-, el hombre depende de la acción, de la transformación inteligente de cualesquiera circunstancias naturales que se le presen$\operatorname{ten}(2, p .115)$."

Gehlen incorpora decididamente la actividad técnica a las características constitutivas humanas y declina vincularla con la "mera razón" o la "simple utilidad". Encuentra, además, una relación entre técnica y magia.

"La técnica, en una evolución muy prolongada, pasó a ocupar el espacio donde antes - cuando la técnica era sólo fabricación de herramientasimperaba la magia; es decir, el espacio que separaba lo que nos es dado hacer mediante acción inmediata de aquello cuyo éxito o fracaso ya no depende del hombre(2, p. 116)."

La creencia en la ductilidad de la naturaleza en función de nuestras necesidades y deseos parece indicar un a priori común entre la magia primitiva, por una parte, y la ciencia natu- ral y la técnica modernas, por otra. Para los primitivos las fuerzas mágicas no eran arbitrarias ni espontáneas, sino que constituían un automatismo animado inserto en todas las cosas que se podía poner en marcha mediante la fórmula correcta. La "fórmula mágica" se presentaba entonces como una herramienta para acercar las distancias espaciales y temporales.

Actualmente ese espacio ha sido reducido o transformado por la tecnología más moderna. Con la máquina a vapor (obra de James Watt, 1769-1790), y luego el motor de combustión (Benz y Daimler, 1886), la humanidad se liberó definitivamente del reino orgánico como fuente de energía. Por otra parte, con la "cadena de montaje" la técnica logró un "sistema industrial" que mecanizó todos los sectores de la producción, a la vez que inició un intercambio metódico y planificado con las ciencias exactas y naturales. Finalmente, cuando la técnica dejó de ser la mera aplicación de una "ciencia" o teoría pura y de tener un puesto de mera subordinación, pasó a constituir un momento intrínseco de la investigación científica: la técnica devino tecno-logía ${ }^{3}$. A su vez, el conjunto de la ciencia, aplicación y reutilización técnica y aprovechamiento industrial se convirtió en una superestructura: el gran aparato industrializado tecnocientífico.

\section{La racionalidad tecnológica}

El hombre actual no hace sino afianzar este "ser práxico", precisamente porque su existencia está marcada y determinada plenamente por el hecho tecnológico. No se trata sólo de que el hombre utilice la tecnología para mejorar sus condiciones de vida o su dominio de la realidad, sino que el hombre se ha convertido en un "ser-en-la-técnica", en la medida en que ésta ha llegado a ser un factor esencial en su modo de ser-en-el-mundo(3). La amplitud de este fe-

3 Gehlen denomina "tecnología" al gran aparato industrializado de tecnociencia. 
nómeno "tecnológico" afecta a todos los ámbitos de la vida, de tal modo que se puede decir que la racionalidad contemporánea se constituye como una "racionalidad tecnológica"4

Se trata de una racionalidad caracterizada por su operatividad práctica, es decir, por la utilidad pragmática del conocimiento. Se busca alcanzar una operatividad y una eficacia máximas, que sean inmediatamente verificables. El confín neto que separa lo deseable de lo imposible sólo está delineado por los recursos que se tengan, por las habilidades técnicas o por el conocimiento a disposición.

Por otra parte, esta racionalidad busca ineludiblemente su expansión a la máxima realidad posible, en el orden cualitativo y cuantitativo. Esto permite una retroalimentación en el sistema tecnológico, pues al incrementarse nuevas capacidades de acción se crean nuevas técnicas aplicables a otros objetos, ensanchándose continuamente bajo su control los límites de la realidad. Según este "imperativo tecnológico", hay que hacer todo lo que se puede, es decir, desarrollar todas las potencialidades de la materia, del viviente y del ser pensante.

A su vez, la "razón tecnológica" - como razón manipuladora y transformadora de la realidad-constituye no un mero modus operandi sino un modus essendi que instaura una mediación epistemológica entre el hombre y la realidad(3, p. 209). A diferencia del "instrumento", que se usa y se abandona una vez utilizado, la mediación acompaña permanentemente al hombre por constituir una dimensión antropológica que no puede ser abandonada voluntariamente.

Por este carácter transformador, la racionalidad tecnológica se asume finalmente como

4 En las ciencias sociales y humanas se habla, por ejemplo, de "tecnologías educativas", de "técnicas psicológicas". una "voluntad de poder" sobre la realidad en todos sus aspectos, desde los objetos materiales hasta los sociales. Constituye, de este modo, la culminación del programa epistemológico de la modernidad: conocer para prever y dominar la naturaleza. Pensemos, por ejemplo, en el Proyecto Genoma Humano.

Ahora bien, como toda forma de racionalidad responde al conjunto de exigencias sociales, políticas y económicas de su tiempo, la realización histórica de este paradigma tecnológico no puede llevarse a cabo al margen de éstas.

\section{Trascendencia "técnica" u "operatoria"}

Ya señalamos cómo, a través de la acción (es decir, de una actividad técnica inventiva), el hombre busca trascender las condiciones de la existencia que le han sido impuestas. Sin embargo, esta intervención -que hasta hace unas décadas era una actividad de orden y organización- ha devenido hoy una actividad de transformación y de manipulación de la naturaleza, incluso la humana. El motor de esta superación parece residir ahora en una "trascendencia operatoria", expresión de ese potencial de investigación y desarrollo tecnocientífico(4).

Una repercusión de esta dirección se ve claramente en la ciencia-ficción ${ }^{5}$. Se sueña seguramente con la inteligencia artificial de los ordenadores del futuro, aunque esta trascendencia operatoria en la humanidad, más que concebirla bajo el ángulo de la sustitución masiva (robots que reemplazarían al hombre), se la considera bajo aquél de la co-evolución progresiva y continua que se ensaya con pequeños saltos mutacionales en las direcciones más diversas y que, eventualmente, pueden despejar

5 Aunque los prejuicios culturalistas tradicionales de algunos autores consagren estas aventuras a menudo al fracaso. 
una línea dominante de fuerzas ${ }^{6}$. Al modo de la otrora vinculación entre técnica y magia, hoy se reactualiza este nexo entre la tecnociencia y la ficción, a la que Hottois ${ }^{7}$ llama "ciencia-enficción".

En este sentido, la "trascendencia operatoria" bien puede ser comparada a la "utopía" como "operador de trascendencia"(5). En efecto, la utopía se presenta no sólo como un pensar funcional sino como una manera necesaria de pensar por constante superación, que recorre un triple estadio: crítico de la realidad existente; imaginativo, como ruptura con lo existente para abrirse a lo nuevo; y constructivo o normativo que, al intentar dar forma a lo "imposible", se plasma en un conjunto de representaciones y/o proposiciones susceptibles de concretarse en un nuevo cuadro de vida.

"El ritmo ternario de la función utópica mostraría un paradigma de la operatividad espiritual, una especie de modelo regulador teórico, aplicable por el pensamiento a todo el conjunto de la actividad humana, sin que por eso deba confundírselo con un instrumento de acción concreta en lo cotidiano. Podría designarse a este paradigma como el método para marchar y no para dar por terminada la marcha, como itinerancia rítmica del espíritu humano que está llamado a no detenerse nunca en el camino(6)."

De este modo, el pensar utópico deviene un mecanismo operativo esencial del hombre o, por decirlo de otro modo, es el hombre mismo en actividad.

6 El "imaginario" de la ciencia-ficción se expresa a veces bajo una des-materialización progresiva, pasando sucesivamente por estructuras soportes del espíritu infinitamente más extendidas, más potentes y más durables que los cerebros humanos, para terminar en entidades también tan especulativas como las estructuras dinámicas del tiempoespacio.

7 Siguiendo a C.P. Snow.

\section{Los avatares de la evolución}

El proceso evolutivo, que se extendiera durante millares de años, parece haber logrado un punto fundamental con la aparición de la especie humana. Sin embargo, el paso de la "especificidad de los instintos animales" a la "carencia" de los mismos en el hombre hace que éste se ubique mal en la hipótesis evolucionista. En efecto, la no-especialización de los órganos y el retardo en el proceso biológico humano no representan una ventaja en la lucha por la existencia, no concurren a un mejor nivel de adaptación, ni tanto, menos favorecen el proceso de selección natural. Por esto, es problemático describir al hombre en término de evolución lineal y explicar el origen a través de leyes de selección y adaptación(7). La bioevolución toma una vuelta (Umschlagen), una inversión (Verkehrung), una involución (Rückbildung) en el hombre, dirá Gehlen. A fin de lograr la supervivencia humana, que no puede ser garantizada por una refinada disposición instintiva ni por una mejor especialización de los órganos, el hombre cuenta con esa relación peculiar entre el cuerpo y el mundo que se caracteriza por ser acción, y no reacción como en los animales. Se abre paso entonces un nuevo proceso -la logo-evolución- donde las grandes transformaciones biofísicas dejan lugar a las realizaciones simbólicas: es el largo camino que van recorriendo los distintos tipos humanos, que se denomina "humanización".

Ahora bien, si desde una perspectiva antropocéntrica la aparición de la especie humana constituye el vértice del proceso evolutivo, después del cual no hay transformaciones biofísicas sino realizaciones simbólicas a lo largo de una historia, para una perspectiva evolucionista ésta constituye sólo un lapso sin duda específicamente humano pero extraordinariamente breve, precedido de una prehistoria extraordinariamente larga y eventualmente seguida de una evolución posthistórica. La histo- 
ria constituiría el tiempo de las modificaciones culturales, simbólicas y de invención de técnicas instrumentales, sin capacidad de mutación profunda en el ámbito material, viviente natural y humano. Se inscribiría aquí un tipo de "trascendencia simbólica", mediada por el lengua$\mathrm{je}^{8}$, dado que la actividad "langagière" ha sido y es la matriz del progreso de las instituciones culturales. En este nivel, ¿qué consecuencias traería aparejada para la libertad la informatización progresiva de la sociedad? ¿Qué consecuencias ocasionaría el desarrollo progresivo de lenguas artificiales y operacionales aprendidas por los niños desde sus primeros años, las cuales podrían sustituir parte por parte el lenguaje diario caracterizado por la polisemia, la flexibilidad, la libertad semántica? ¿Qué consecuencias acarrearía la ampliación de los vínculos entre el cerebro y la computadora?

En la medida en que las actuales investigaciones tecnocientíficas han logrado sobrepasar las modificaciones históricas y culturales, políticas y sociales, propias de la "trascendencia simbólica", pueden considerarse verdaderas mutaciones, no-espectaculares pero sí acumulativas como en el proceso evolutivo. Se trata ahora una tecnoevolución(8) que recién comienza, y de la cual no se sabe si será diferente de la evolución histórica o si tendrá las mismas consecuencias que la evolución biológica. De este modo, experimentando por ensayo y error, el hombre no hace sino continuar un trabajo análogo al que la naturaleza realizara en el curso de la evolución al precio de millares de tentativas.

De esta evolución posthistórica nada podemos anticipar. Más aún, las direcciones actuales de las tecnociencias del viviente parecieran hacer "estallar los cuadros del humanismo y antropocentrismo", conduciendo "al hombre más allá del hombre, fuera del hom-

8 Con esto, no se trata de instaurar una inflación del lenguaje. bre, no necesariamente en (dans) lo in-humano sino hacia (vers) lo ab-humano, lo otro que la naturaleza o especie humana( $8, p .91)$. Aquella vía respetuosa del "dato natural" deja su lugar a la "trascendencia operatoria", cuyas vías a lo absoluto o a lo otro pasan por refundiciones radicales e indefinidas respecto de la naturaleza y de la esencia humana: transformación de los modos de transmisión de generación en generación, de los genes en todas las especies vivientes, del cuerpo y del cerebro humano, de los modos de comunicación e interacción entre éstos, por no seguir con un largo etcétera.

Peculiar paradoja ésta, el hombre no sólo transforma el mundo sino que él mismo es objeto de transformación; se ha convertido en una materia cada vez más plástica hasta acabar siendo un hombre remodelable, deconstruible, manipulable. El "hacer", investido ahora de la idea de un progreso sin límites, pareciera capaz de realizar y cumplir con el fin último al cual tiende el hombre: la felicidad, según indicaba Aristóteles.

La ética tradicional preveía un agente moral que debía regular sus relaciones siempre con sus propios semejantes, en un tiempo que no superaba la duración de una vida, por lo cual el saber solicitado al actuar moral no exigía competencia ni conocimientos especializados. Pero hoy el ámbito circunscrito de la intención y de la acción, que rige la ética, está fuertemente atravesado por efecto del hacer técnico cuyas producciones van mas allá del actuar humano. La tecnociencia actual condiciona y cuestiona a la ética obligándola a tomar posición sobre una realidad que ya no es más natural sino artificial, que ella no cesa de construir y hacer posible, cualquiera sea la posición asumida por aquélla.

Ante esto surge un temor debido a la indefinición misma de sus consecuencias. Caben en- 
tonces dos alternativas, la de los enfrentamientos y desgarros, o la del debate sereno y argumentado de cada situación.
La "legitimación" de la tecnociencia no necesariamente debe llevar a una limitación de sus desarrollos e investigaciones, so pena de caer en un nuevo "malestar de la cultura".

\section{Referencias}

1. Gehlen A. El hombre. Salamanca: Editorial Sígueme; 1980: 18.

2. Gehlen A. Antropología Filosófica. Barcelona: Paidós; 1993.

3. Queraltó Moreno R. Racionalidad tecnológica y mundo futuro: La herencia de la razón moderna. Seminarios de Filosofía 1998: 11: 203-219.

4. Hottois G, (ed.) Philosophie et science-fiction. Paris: Vrin; 2000.

5. Breton S. Théorie des idéologies. Paris: Desclée; 1976.

6. Briancesco E. Pensar la Utopía. Teología 1979; XVI(33).

7. Galimberti U. Psique e techne. L'uomo nell'età della tecnica. Milano: Feltrinell Editore; 1998.

8. Hottois G, (ed.) Evaluer la technique. Paris: Vrin; 1988.

\section{Bibliografía}

Albertini A. Biotecnologie e paesi in via di sviluppio. En: Rodotá S, (comp.) Questioni di bioetica. Bari: Laterza; 1993: 289-300.

Bauman Z. La società dell'incertezza. Bologna: Il Mulino; 1999.

Bianca M. Scienza, etica e bioetica. Firenze: Angelo Ponte Corboli Editore; 1999.

Bonilla A. La neutralidad axiológica de la ciencia como problema. En: Rovaletti ML, (ed.) Ética y psicoterapia. Buenos Aires: Biblos; 1995: 21-27.

Casado M, Godoy Duarte R, (ed.) Los retos de la genética en el siglo XXI. Genética y Bioética. Barcelona: Universidad de Barcelona; 1999.

Chanteur J. La thérapie génique, les manipulations génétiques et l'étique. En: Del Tacca M. (comp.) L'etica nella ricerca biomedica. Roma: La Nuova Italia Scientifica; 1997: 137-148.

D’Agostino F. Etica nella ricerca scientifica. En: Del Tacca M. (comp.) L'etica nella ricerca biomedica. Roma: La Nuova Italia Scientifica; 1997: 59-68.

De Carli L. Etica nella ricerca sul genoma umano. En: Del Tacca M. (comp.) L'etica nella ricerca biomedica. Roma: La Nuova Italia Scientifica; 1997: 149-164.

Escudé Casals J. Una ética para la era tecnológica. Cuadernos del Programa Regional de Bioética 1997; 5: 63-84. 
La odisea de la especie: El porvenir lejano de la humanidad - M. Rovaletti

Hottois G. Essais de Philosophie Bioéthique et Biopolitique. Paris: Vrin; 1999.

Hottois G. Liberté, humanisme, évolution. En : Hottois G. (ed.) Evaluer la technique. Paris: Vrin; 1988: 85-96.

Lacadena J. Genética, Sociedad y Bioética. En: Palacios M, (coord.) Bioética 2000. Madrid: Ediciones Nobel; 2000.

Ladrière J. L 'Ethique dans l'universe de la rationalité. Québec: Editions Artel-Namur, Fides y Artème Fayard: 1997.

Ladrière J. Les enyeux de la rationalité. Le défi de la science et de la tecnologie aux culture. Paris: AubierUNESCO; 1977.

Lenoir F. Le temps de la responsabilité. Entretiens sur l'éthique. Paris: Fayard; 1991.

Muñoz E. Los cultivos transgénicos y su relación con los bienes comunes. En Palacios M, (coord.) Bioética 2000. Madrid: Ediciones Nobel; 2000.

Nossal GJV. Los límites de la manipulación genética. Barcelona: Gedisa; 1997.

Pessina A. Bioetica. L'uomo sperimentale. Milano: Bruno Mondadoni; 1999.

Puytorac P. De la biophilosophie à une ethique de la biologie: la societé face a la biologie. Paris: L'Harmattan ; 1998

Rovaletti ML. Más allá de la enfermedad: las prerrogativas de la biomedicina actual. Acta Bioethica 2000; VI(2): 309-319.

Sachetti A. L'uomo antibiologico. Riconciliare, società e natura. Milano: Feltrinelli; 1999.

Schramm FR, Kotow M. Bioética y Biotecnología: lo humano entre dos paradigmas. Acta Bioethica 2001; VII(2): 259-276.

Vergote HB. L'artifice et le faux prestiges du naturel. En: Hottois G, (ed.) Evaluer la technique. Paris: Vrin; 1988: 117- 132. 